\title{
META-ANALYSIS: THE EFFECT OF BUPROPION ON THE EFFORT TO QUIT SMOKING
}

\author{
Muhammad Zainul Lafifi), Bhisma Murti1), Hanung Prasetya²) \\ ${ }^{1)}$ Masters Program in Public Health, Universitas Sebelas Maret \\ 2)Faculty of Medicine, Universitas Sebelas Maret
}

\begin{abstract}
Background: Smoking remains the single most important cause of premature death in both developed and developing countries. Many approaches to increase smoking cessation rates have been studied, including use of antidepressant medications. Recent studies have reported that bupropion hydrochloride, an antidepressant chemically unrelated to other antidepressants, may be useful in increasing smoking cessation rates among smokers. The objective of this study was to investigate the effect of bupropion on the effort to quit smoking.

Subjects and Method: A systematic literature search was conducted in multiple databases including PubMed, Science Direct, Google Scholar, Springerlink, and complemented by cross-referencing to identify randomized control trial published from 2011 to 2021. The following search terms were used: ("bupropion") AND ("smoking cessation") AND ("randomized controlled trial"). The articles were filtered using PICO model, including: (1) population= adult active smokers aged $\geq 18$ years, (2) intervention $=$ bupropion, (3) comparison $=$ placebo, and (4) outcome $=$ smoking cessation. The inclusion criteria were English full-text, randomized controlled trial, and reported mean and standard deviation. The study instrument for assessing smoking cessation was Fagerstrom test for nicotine dependence. The systematic review was carried out according to the PRISMA guidelines. Data analysis were performed using RevMan 5.3.

Results: This study involved 6 studies from United States, United Kingdom, and Turkey. This study showed that bupropion reduced smoking behavior 0.29 units than placebo (SMD= $-0.29 ; 95 \% \mathrm{CI}=-0.46$ to $-0.12 ; \mathrm{p}=0.005$ ).
\end{abstract}

Conclusion: Bupropion reduces smoking behavior than placebo.

Keywords: bupropion, smoking cessation, quitting smoking

\section{Correspondence:}

Muhammad Zainul Lafif. Masters Program in Public Health, Universitas Sebelas Maret. Jl. Ir. Sutami 36A, Surakarta 57126, Central Java. Email: zainullafif@student.uns.ac.id. Mobile: +6282137179433 . 